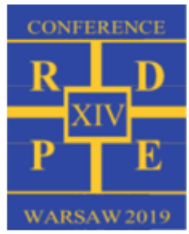

\title{
Pilot installation for thermal utilization of meat-and-bone meal using the rotary kiln pyrolyzer and the fluidised bed boiler
}

\author{
M arcin K antorek ${ }^{1}$, K rzysztof J esionek ${ }^{2}$, Sylwia Polesek-K arczewska ${ }^{3}$, Paweł Ziółkowski ${ }^{4,}{ }^{*}$, Michał Stajnke ${ }^{3}$ and Janusz \\ B adur ${ }^{3}$ \\ ${ }^{1}$ Endress+Hauser, Wołowska 11, 51-116 Wrocław, marcin.kantorek@ gmail.com, Poland \\ ${ }^{2}$ Wrocław University of Science and Technology, Wybrzeże Wyspiańskiego 27, 50-370 Wrocław, krzysztof.jesionek@ pwr.edu.pl, \\ Poland \\ ${ }^{3}$ Institute of Fluid-Flow M achinery, Polish A cademy of Sciences, Fiszera 14, 80-231 G dańsk, sylwia.polesek- \\ karczewska@imp.gda.pl, michal.stajnke@imp.gda.pl, jb@imp.gda.pl, Poland \\ ${ }^{4}$ Gdańsk University of Technology, Faculty of M echanical Engineering, Department of Energy and Industrial A pparatus, Narutowicza \\ 11/12, 80-233 Gdańsk, e-mail: pawel.ziolkowski1@pg.edu.pl, Poland.
}

\begin{abstract}
The technology of thermal utilization of meat-and-bone meal (M B M ) is still at the research state. However, there are already a number of existing pilot-scale installations that provide the complete, effective and environmentally safe process conducting. The universal technology was developed that allows to combust various types of waste, including animal waste, municipal waste and sludge, mixed at any ratio with different types of biomass. It provides the possibility to utilize the waste-and-biomass fuel mixtures of up to $90 \%$ wt of moisture content, while maintaining the al lowable pollutant emission to the atmosphere and soil. This regards mainly $\mathrm{NOx}, \mathrm{SO}_{2}, \mathrm{HCl}$ and $\mathrm{VOC}$. Contrary to the typical large scale grate boilers used for waste incineration, the developed operating pilot-scale plant with a capacity of $12 \mathrm{M} \mathrm{W}$ offers the complete combustion of animal meal, resulting in a flue gas which is proved to be free of flammable gaseous components and sooty particles in slag and fly ash. The thermal decomposition and combustion of waste using this technology ensures thermal conversion of chemical energy contained in waste and biomass into the heat and electricity, while preserving the optimum thermodynamic efficiency of technological system. The efficiency of the prototype installation varied between 88.36 and $84.84 \%$ depending on the load.
\end{abstract}

\section{Introduction}

A n increasing worldwide production of meat leads to an increased amounts of animal waste that require management. Due to the risk of the B ovine Spongiform Encephalopathy (BSE) that arised in 1980s and 1990s, this type of waste started being considered as hazardous [1-3]. Since then, implemented regulations, restricted its use as an additive to cattle feed and direct disposal in landfilling as natural fertilizer [4-5].

Addressing the need for environmentally safe destruction of this type of waste, including meat-and bone meal (M B M ), the efforts have been undertaken to develop efficient thermochemical technologies that would allow their energy utilization with low emissions [6-10]. Since MBM is classified as hazardous, its thermal utilization requires special processing conditions, namely, relatively high temperatures (above $800^{\circ} \mathrm{C}$ ) and appropriate residence time. Therefore it used to be incinerated in cement kilns $[11,12]$. MBM is also considered as an alternative fuel in combustion and co-combustion with other solid fuels. This include the combustion in grate boilers [13], as well as in fluidized bed combustors [1, 5, $11,14]$, which offer high process temperatures and long residence times [15]. Combustion of MBM as the save disposal method is al so justified due to valuable properties of its ashes, which being free from harmful pathogens may serve as fertilizer [16].

To carry out environmentally sound and efficient thermal conversion of meat industry by-products that would meet the regulations, the in-depth recognition of sub-processes and phenomena occurring during the process is needed. This also refers to the material properties and behavior as the basis for the determination of the potential use of this kind of waste for energy purposes $[3,18]$. This has contributed to the development of technology, which proved to be thermodynamically efficient and to provide low levels of contamination and dust emissions. The paper presents the detailed characteristic of the system and shows the key performance parameters of a pilot-scale facility of $12 \mathrm{M} \mathrm{W}$ capacity.

\section{Description of a system}

The described herein technology provides the possibility to incinerate not only the animal waste, but also other types of organic waste such as sewage sludge, municipal waste and biomass of different kind. Its application allows to utilize the biodegradable waste of the overall moisture content up to $90 \% \mathrm{wt}$ and whilst preserving the maximum allowable levels of atmosphere and soil contamination. 


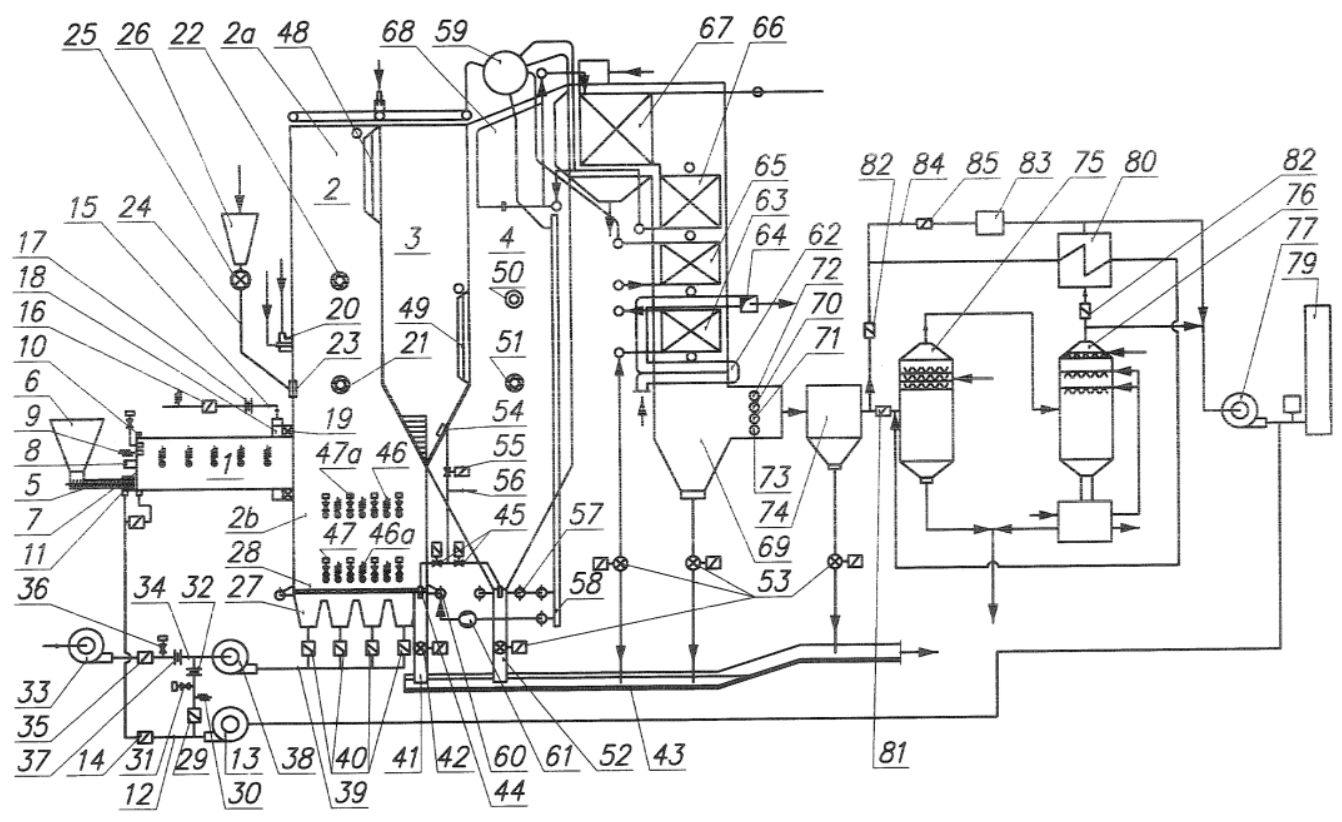

Fig. 1. The schematic of the installation for thermal utilization of meat-and-bone meal.

The energy recycling of hazardous and nonhazardous waste implementing the two-stage technology that use the rotary reactor to pyrolyze the feedstock and the fluidized bed chamber to combust the pyrolysis gas and the remaining char, ensures thermal conversion of waste with flue gases free from any environmentally harmful dioxins and furans. The combustion process is supplemented with the liquid or gas fuel, which is added in an amount ranging from 0.015 to $0.070 \mathrm{~kg}$ per kilogram of a feedstock, depending on its moisture content. The physical structure of waste to be utilized may be solid, as well as in form of a pulp or a dense slurry. In each case, the technology provides the optimum thermal effect. In view of this, the presented waste/biomass-to-energy technology allows to obtain the maximum levels of thermal efficiency and protection to the environment and human health and, additionally, the optimum economical effect.

The primary fuel in this case is an animal waste, biomass of different kind and alternative fuels. As aforementioned, the auxiliary fuel used to initiate the process is either gas or liquid fuel. However, it is preferable to use the renewables as supporting fuels since all the energy generated in the system would then come from the renewable energy sources. The minimum amount of feedstock material for which the installation can be operated is $20 \%$ of its nominal efficiency, whereas maximum reaches $150 \%$ at a moisture content of $80 \%$.

The combustion takes place under conditions that comply with the relevant requirements of the directives and regulations concerning the safe utilization of animal waste. Namely, it is carried out at temperatures higher than $850^{\circ} \mathrm{C}$, with oxygen content exceeding $8 \%$ and the residence time longer than 2 seconds.

The reported method of thermal utilization is a continuous-type process that proceeds in a system of integrated devices. These are equipped with measuring and control instruments for reading local parameters and remote transmission of signals to control units. Automatic control is performed according to the prescribed operation algorithm. The control system covers the course of a technological process, its visualization, archiving of operation parameters and occurring events, and monitoring of parameters of substances leaving the installation. And thereby, it enables direct and immediate interference with the process course in order to preserve the required parameters.

The schematic of the installation for thermal utilization of animal waste, including the rotary pyrolyzer and the fluidized bed boiler is shown in Fig. 1. The MBM to be burnt is fed into the boiler storage tank (6) together with the limestone in a quantity corresponding with a stoichiometric ratios needed to neutralise the sulphur and chlorine content in a fuel. They are mixed there and then transported by the fuel feeder (5) into the rotary kiln pyrolyzer (1). The mixture falls into the pyrolyzer chamber via the chute of a feeding unit. In order to ensure an even fuel feed into the chamber, the waste is supplied in a stream of flue gases that flow in a gas-box (11) surrounding the feeder. The exhaust gas is pumped through the pipeline (12) into the gas-box using the recirculation fan (13), and taken out using the suction fan (77). The amount of flue gas required for the process is adjusted by opening or closing the flap (14).

On the side of fuel charging system, the rotary pyrolysis chamber is closed by a flat front panel (7), which is connected to the chamber through the channel with a labyrinth sealing (10) that is filled with recirculating exhaust gas. Its quantity is controlled via an adjustable slide. In a central axis of the flat front panel is located a supporting burner (gas or oil) (8), used to provide the appropriate thermal conditions for drying and pyrolysis of 
a fuel. The panel is also equipped with a thermocouple (9) and a pressure plug. The other end of a rotary chamber is connected to the fluidized bed chamber (2). This connection is additionally sealed through an air canal (18) equipped with a swirl unit (19) and the compensating slides of vertical elongations. The canal is supplied with air through the pipeline (15) fitted with the measurement orifice (17), the regulation flap (16) and a thermometer. In order to ensure the correct course of drying and devolatilization in a rotary chamber, the fuel feedstock is raised up to over $70 \%$ of the chamber diameter by the specially designed lifting flights mounted inside. This limits the possibility of sintering and agglomeration of a feedstock, and thereby intensifies the heat transfer within the material and promote the moisture and gas release. Additionally, along the rotary chamber centreline the thermometers are located to control the processing temperature. This, in case of thermal utilization of meat meal, should remain between 900 and $1200^{\circ} \mathrm{C}$. The thermometers enable the proper control of a supplying burner operation so as to ensure the relevant temperature distribution. The rotation speed of a pyrolyzer within a range between 0.5 and $5 \mathrm{rpm}$ provide the residence time of a char in a chamber at the level ranging from 5 to 10 minutes.

Gas mixture and solid carbon residue resulted from the drying and pyrolysis of a meat meal are directed to the fluidized bed chamber. It is built of a sealed membranetype walls bearing a heating medium. Pyrolysis gas is supplied to the upper part of a chamber and combusted there, whereas char is burned in a fluidized bed in a hopper-shaped lower part of chamber. At the bottom, the chamber is closed by the orifice plate (28), which is covered with a refractory concrete on the fluidized bed side. The orifice plate is closed by a wind box (27), which is divided into a number of sections to allow the adjustment of pressure and the gas flow in each bed zone. The amount of gas supplied to each zone is controlled by opening and closing the flaps (40). It flows in from the collector (39), which is fed by the fluidizing fan (38) with adjustable settings of gas efficiency and pressure. The fan draws in the flue gas from the damper located downstream of the sucking fan (13). The flue gas is supplied to the fan through the duct equipped with the shut-off and/or regulatory slide (29), the thermometer (30), the manometer (31) and the measurement flange (32). To generate the fluidizing gas, the blower (33) provides additional air supply to the fluidizing fan. Air is transported via the pipeline (34), similarly having the shut-off and/or regulatory slide (35), the manometer (36) and the orifice (37). The exhaust and air fans are equipped with the systems for adjusting the quantity and the pressure of supplied media.

The residual ash is removed from the fluidized bed using an ash discharging system, comprising the discharge channel (41) and the remotely operated rotary feeder (42). The channel is situated next to the vertical rear wall of a fluidized chamber hopper. Ash is then directed to the bucket feeder (43), which is placed in a water tank that serves as a water trap for a fluidized bed chamber. The ash discharge channel is also equipped with a compressed air impulse nozzle (44) operated by a remote shut-off valve (45), which supports the ash removal efficiency.

The lower zone of a chamber, namely the fluidized hopper is formed by a vertical front and rear walls, and the side walls inclined toward the chamber centre with an inclination angle less than $45^{\circ}$. The hopper is insulated with a refractory concrete to protect metal elements of the walls from erosion.

To ensure the proper operation of a fluidized unit, the hopper is equipped with a relevant measuring system allowing to monitor the bed parameters, and to determine the fluidizing gas composition and the amount of inert material. The system include the temperature sensors (46) and (46a), as well as the manometers (47) and (47a), evenly spaced across the left and right inclined walls of a hopper. Manometers and thermocouples are spaced alternately in a horizontal plane at two heights, namely at the distance of $200 \div 500 \mathrm{~mm}$ and $2 \div 4 \mathrm{~m}$ above the orifice plate. Both, the lower and the upper measuring points in a vertical plane are positioned in pairs to enable the differential pressure measurement in a bed.

As aforementioned, a fluidized bed is generated in a chamber hopper as a result of a fluidizing gas flow i.e., the air/flue gas mixtures with the volumetric ratios ranging from $10 \% / 90 \%$ to $90 \% / 10 \%$, through the inert bed material. This is composed of a mixture of silica sand and properly grinded slag, which is blended with limestone in its mass fraction ranging from 2 to $80 \%$, depending on the sulphur, chlorine and the fixed carbon contents in a fuel. The material is fed into the fluidized bed chamber periodically through the inlet window (23) from the storage tank (26) and through the duct (24) with a rotary feeder $(25)$.

The flow velocity of a fluidizing gas through the bed, lies in a range between 1 and $4 \mathrm{~m} / \mathrm{s}$, regardless of the heat load. The fluidization process must be conducted in such a way that the temperature in a bed does not exceed the characteristic ash softening temperature. The process temperature ranges within 750 and $900^{\circ} \mathrm{C}$, and the volumetric fraction of oxygen in fluidizing gas varies between 2 and $20 \%$.

As already stated, the pyrolysis gas is combusted in the upper zone of a fluidized bed chamber. The process is carried out with the use of a burner (20) mounted in a front chamber wall. The burner is powered by liquid or gas fuel and is needed to ignite and stabilize the process of gas combustion. This is conducted at temperatures of $1200 \div 1300^{\circ} \mathrm{C}$ and must be controlled so as not to exceed the maximum of $1300^{\circ} \mathrm{C}$ that fosters rapid formation of nitrogen oxides. To provide the process control the combustion air is distributed. The primary air is supplied through the sealing channel (18) equipped with a swirl vane, which connects the rotary pyrolyzer to a fluidized bed chamber. This air amounts to $0.2-0.4$ of the stoichiometric air needed to burn the meal. Of the same quantity are also supplied the secondary and the third air streams, by the nozzles (21) and (22), respectively. Such air distribution helps to extend the combustion zone, leading in result to volumetric heat load of a chamber that allows to prevent from exceeding $1300^{\circ} \mathrm{C}$ in a burning zone. 
Exhaust gases are directed through the upper festoon (48) to the separation chamber (3). The festoon is made of three rows of wall tubes of a separation chamber, to which the U-profiles are attached. These, with their open parts face the flue gas inflow, allowing the precipitation of particulates and the condensation of alkali and heavy metals' vapours. When hitting the U-profile, the exhaust particles decelerate and fall back along the section down to the bed. The heavy metals' vapours condense on a profile wall forming a glassy-like deposit, which is blown away downwards back to the bed with soot blower installed on a top of a chamber, above the festoon tubes. The separation chamber which constitutes the rear chamber wall, is closed by a baffle placed in front of rotary pyrolyzer and the chamber walls. The baffle, being bended in its lower part towards the chamber rear wall at a maximum angle of $45^{\circ}$ serves as a tightly closing heated membrane-type surface. The bended baffle surface has the discharge hoppers along the chamber width to drive back the separated particles to the bed using compressed air supplied by the impulse nozzles (54). Rear wall of a fluidized bed chamber is of similar shape, however bended towards opposite direction it closes the separation chamber. The bendings are covered with refractory cement protecting them against erosion. Exhaust gases, partially purified of solids and vapours, change direction when passing upper festoon and flow through the separation chamber. There, due to change in direction and reducing the flow velocity, they are further de-dusted. Next, the treated flue gas flows through the lower festoon (49) to the afterburner chamber (4). The burn out of combustible gases remaining in a flue gas is carried out using oil or gas burner (50), ensuring ignition and the process stabilization. The complete burnout is provided by mixing the exhaust gases with an additional (fourth) air dosed by a nozzle (51) at the amount ranging from 0.1 to 0.3 of stoichiometric quantity.

There is a bulkhead superheater (68) mounted in an upper part of the afterburning chamber, and the second stage superheater (67) with the vapour temperature controller placed in a crossover duct. There are the first stage superheater (66), the water heaters (65) and (63), and the air heater (64) placed in a convection channel. Fumes, free from gaseous and solid combustible components, give off the heat by convection when flowing through the system. They are analysed at the outlet of the convection part. i.e., in an exhaust duct, in terms of their chemical composition, ash content, pressure and temperature, using spigots (70)-(73), respectively.

Flue gas flowing out of a boiler goes next through the fabric filter (74) to remove particulates. Purified gas is next fed to the water sprinkler (75) and the scrubber (76), where the sub-micron solid particles, as well as alkali and heavy metals' vapours are eventually separated, and gaseous molecules of sulphur and chlorine oxides are chemically bonded by a lime slurry sprayed in a scrubber. The parameters of exhaust gases entering the stack are monitored with the use of analyser (78). These include the temperature and the contents of ash and soot, moisture, carbon oxide, sulphur and nitrogen oxides, and hydrocarbons. In case when temperature exceeds the dew point temperature, the fumes flow through an exhaust fan
(77) directly to the stack (79). Otherwise, a flue gas is first directed to the heat exchanger (80) and then to the chimney.

Ash removed from flue gas in the hopper of afterburning chamber, in the discharge hopper of firing zone and convection zones, and in the fabric filter, similarly as in the case of fluidized bed chamber, is conveyed through the channels equipped with rotary feeders. It further goes to a bucket feeder and finally to a disposal site. As regards the water circulation system, the medium is transferred from the heater to the drum (59), from which it is supplied through the down-comers (58) to the wall tube manifold of afterburning chamber (57) and the wall tube manifold of fluidized bed chamber (60). The steam generated in a boiler goes back to the drum, and then is directed to the superheaters and the turbine. The medium flow in a fluidized bed chamber is forced by a water circulation pump (61).

\section{Pilot-scale installation of $12 \mathrm{MW}$ capacity}

An experimental facility was built in the town of Ostrowite, the Lniano municipality, in Kujawy and Pomerania Province. It was developed to serve as a source of thermal energy in the form of steam for technological use in an animal waste treatment plant. The installation continuous to operate. The system consists of the rotary pyrolyzing reactor, the fluidized bed chamber and the waste heat recovery boiler. As described previously, drying and devolatilization are carried out in a pyrolyzer, whereas the fluidized bed chamber is used to combust the pyrolysis products, namely the gas components in its upper zone and the remaining solid (char) in its lower zone. Burning of volatiles takes place in a controlled manner with the multistage air supply. Char combustion in a fluidized bed is controlled by an oxygen concentration in a fluidizing gas, which is a mixture of air and recirculating flue gases. The exhaust gas generated in a fluidized bed chamber, in the first place, undergoes cleaning in a separation chamber aimed to extract the fly ash. After partially purified, the flue gas is directed to the shell-type heat recovery boiler that produces steam at pressure of 5 bars and temperature of $250^{\circ} \mathrm{C}$. The view of the installation is displayed in Fig. 2.

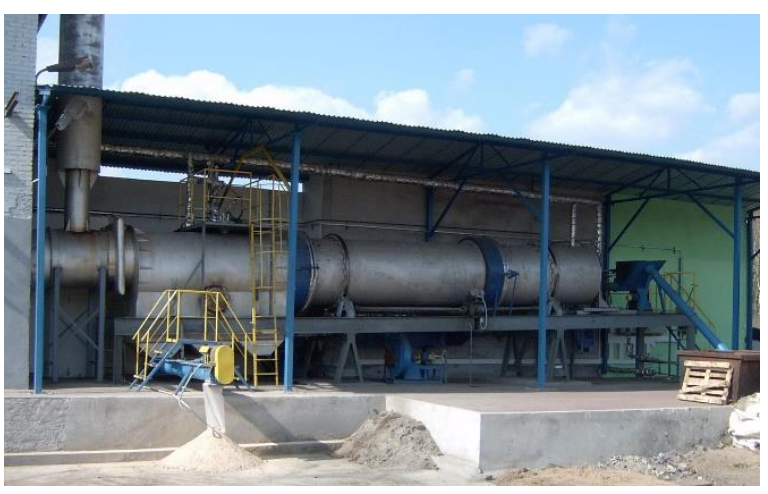

Fig. 2. The general view of the pilot-scale installation.

The presented technology system provides the complete combustion of animal meal and the elimination 
of combustible components from slag and the fly ash, as well as flammable gases from fumes. A s confirmed by the measurements, the installation ensures the emissions of harmful substances below the permissible standards, including $\mathrm{NO}_{x}, \mathrm{SO}_{2}, \mathrm{HCl}$ and $\mathrm{VOC}$. The implemented two-stage technology that utilize the rotary reactor for drying and degasifying waste fuel, and the fluidized bed chamber for separate combustion of pyrolysis gas and char, allows to control the individual stages of fuel combustion. These refer to the chemistry of a process. i.e., an elementary composition of a reactive atmosphere, and to its thermal regime, i.e., characteristic process temperature range.

The commonly used installations for waste incineration based on grate-type boilers do not provide the complete combustion and they generate a slag that contains substantial quantities of combustible components in form of char, exceeding mass percentage of $5 \%$. It consists of carbon in nearly $100 \%$. This slag is thus a waste, which has to be further disposed. In the case of studied prototype system for thermal conversion of waste, particularly the MBM, the remaining ash constitutes a valuable raw material for the production of phosphorous-, potassium- and calcium-magnesium-based fertilizers. The content of phosphates in ash reaches 25 $28 \%$ and is about 5 times higher than typical contents in natural minerals. The obtained ash is a valuable resource, basically due to high levels of $\mathrm{P}_{2} \mathrm{O}_{5}$ and the trace levels of combustible parts remaining at $0.5 \%$ by weight.

In the case of considered prototype installation in Ostrowite, the amount of auxiliary (liquid) fuel ranges between 0.01 and 0.08 kilograms per $1 \mathrm{~kg}$ of a meal, depending on a moisture content in a target waste fuel. In any case, the system provides the positive thermal effect. The heat generated in a furnace is used in a heat recovery boiler that produces steam at the pressure of 4-6 bars and temperature $T=250-300^{\circ} \mathrm{C}$, depending on the technological needs. At the start-up stage, namely at the stage needed to establish the temperature balance in the system, the light heating oil is used. When the assumed temperature in a rotary pyrolysis reactor is achieved, the ignition fuelling system is switched from heating oil to heated animal fat of temperature $T=80^{\circ} \mathrm{C}$. This type of kindling fuel is classified as an alternative fuel from renewable resources, and thereby the total thermal energy generated by the system is regarded as renewable energy. The installation provide high availability and reliability. The minimum quantity of meal required for operating the system amounts to $20 \%$ of a nominal capacity, whereas the maximum corresponds to the nominal capacity of $120 \%$.

As aforementioned, the process of M BM utilization is of continuous-type, and the facility equipped with automatic monitoring and control system based on the prescribed control algorithms allows an on-line adjustment of operating settings so as to meet the required output parameters.

\subsection{Meal supply system}

Meat meal is fed into the hopper of a unit of external conveyors, which transfer the fuel into an interim bunker hopper. From there the meal is fed into a loading hopper of a rotary pyrolyzer. To avoid dust lift-off and the spread of odours, the fuel supply unit is hermetically sealed. Additionally, it is placed in a room with continuous exhaust system of contaminated air, which is further used for fuel combustion. The installation is also fitted with a grate to separate bones exceeding the dimension of $50 \mathrm{~mm}$. The amount of supplied meal is regulated with the use of inverter setting the travelling speed of a feeder.

\subsection{Drying and thermal decomposition}

The processes of drying and devolatilization take place in a rotary kiln reactor with a diameter of $1200 \mathrm{~mm}$. Its chamber is equipped with specially designed material lifters, which are distributed alternately in three sectors along the chamber length. The chamber rotates at 0.5-5 $\mathrm{rpm}$ and is inclined by $2-3^{\circ}$ towards an outlet. It is made from an uncooled pipe with a refractory lining inside and closed by a sealed faceplate from the front. In a faceplate there is installed an oil burner, equipped with the systems of ignition and flame control. There is also mounted the charging device of meal and sorbent. The quantity of liquid fuel to be combusted is automatically adjusted, so as the temperature inside the chamber remains within range between 850 and $1100^{\circ} \mathrm{C}$, according to the type of animal meal being utilized. The amount of air supplied to the rotary kiln pyrolyzer depends on a supplementary fuel quantity and is set to ensure the complete combustion and nearly zero content of oxygen in the drying and pyrolysis zones. The process is carried out in a reductive atmosphere to avoid burning and heat release. The rotary chamber is connected with a fluidized bed chamber via a swirling element for primary air, which is necessary to partially combust evolved pyrolysis gas.

\subsection{Combustion}

Burning of pyrolysis products takes place in several stages in a fluidized bed boiler, which is directly connected to an outlet of the rotary kiln reactor. The boiler chamber is made of tight wall tubes that constitute the evaporator unit. At the chamber wall in a fluidized bed zone there is installed a burner for igniting and stabilizing combustion. There is an orifice plate at the chamber bottom, which provokes fluidization. It is composed of several sections, inclined towards an ash discharge hopper. The postpyrolysis char is combusted in a fluidized bed, whereas pyrolysis gas is burnt in the upper part of a chamber in its consecutive sections being supplied with primary, secondary and the third air, respectively. Temperature in a flame zone is within 1100 and $1300^{\circ} \mathrm{C}$, and an oxygen content in a flue gas amounts to $7-8 \%$. Temperature inside a fluidized bed ranges between 700 and $950^{\circ} \mathrm{C}$ and is being set according to ash softening characteristics. An excess-air ratio is within 1.1 and 1.25 , whereas an oxygen content in a fluidizing gas is $6 \%$. The residence time of pyrolysis gas in a fluidized bed chamber at the required temperature range of $1200-1300^{\circ} \mathrm{C}$ is $4-6$ seconds. The residence time of the solid pyrolysis residue in a fluidized bed is about 10 minutes. The exhaust gases leaving the chamber, being next treated when passing through the 
separation chamber, flow to the waste heat recovery boiler.

\subsection{Tests of the facility}

Experimental study of combustion of animal meal blends in the prototype installation was performed for four different heat loads, corresponding to the meal quantities of 500,1000, 1500 and 2000 kilograms per hour. The chemical composition of examined blend, as well as postcombustion ash were analysed.

The experimental analysis covered mainly the measurement of: i) fuel quantity, ii) temperature inside a pyrolysis reactor and inlet/outlet pressure, iii) pyrolysis gas composition, iv) flue gas temperature and composition, v) steam parameters (output, temperature and pressure) and vi) carbon content in ash.

The performed measurements indicated low levels of $\mathrm{CO}(\sim 0.15 \%)$, relatively low content of $\mathrm{SO}_{2}$ (between 115 and $233 \mathrm{mg} / \mathrm{Nm}^{3}$ ) and constant level of NOx emission $\left(180-221 \mathrm{mg} / \mathrm{Nm}^{3}\right)$ independent on the waste fuel quantity. Also the content of unburned combustibles wass very low, particularly in case of a bottom ash (up to $0.4 \%$ ), regardless of the heat load. In the case of fly ash this content fluctuated between 1.0 and $1.5 \%$.

Simultaneously, the thermodynamic efficiency of a system varied between 88.36 and $84.84 \%$, depending on a thermal input.

\section{Conclusions}

In the paper we present the two-stage technology for waste utilization, which offers the fuel incineration with a maximum available thermal efficiency and the minimum levels of emitted gaseous components and unburned carbon in fly ash. This was confirmed by the tests of animal meal utilization carried out in a pilot-scale installation with an output of $12 \mathrm{MW}$.

The developed technology is universal, allowing to incinerate any waste, as well as any mixtures of waste and biomass.

Acknowledgments: The part of work has been prepared within the frame of 3 institution mainly: IMP PAN, PG and PW.

\section{References}

1. Cascarosa E., Boldrin A., Astrup T., Pyrolysis and gasification of meat-and-bone-meal: Energy balance and GHG accounting, Waste Management, Vol. 33, pp. 2501-2508, (2013).

2. Staroń P., Kowalski Z., Staroń A., Banach M., Thermal treatment of waste from the meat industry in high scale rotary kiln, International Journal of Environmental Science and Technology, Vol. 14, pp. 1157-1168, (2017).

3. Kantorek M., Jesionek K., Polesek-Karczewska S., Ziółkowski P., Thermal utilization of meat and bone meals. Performance analysis in terms of drying process, pyrolysis and kinetics of volatiles combustion, Fuel, Vol. 254, 115548, (2019).
4. Campbell W.A., Fonstad T., Pugsley T., Gerspacher R., MBM fuel feeding system design and evaluation for FBG pilot plant, Waste Management, Vol. 32, pp. 1138-1147, (2012).

5. Gulyurtlu I., Boavida D., Abelha P., Lopes M.H., Cabrita I., Co-combustion of coal and meat and bone meal, Fuel, Vol. 84, pp. 2137-2148, (2005).

6. Poskrobko S., Identification and stabilization of combusting animal waste with active participation of bone material - Emission of $\mathrm{SO}_{2}$ and HCl, Fuel Processing Technology, Vol. 113, pp. 20-27, (2013).

7. Lopes H., Gulyurtlu I., Abelha P., Crujeira T., Salema D., Freire M., Pereira R., Cabrita I., Particulate and PCDD/F emissions from coal cofiring with solid biofuels in a bubbling fluidised bed reactor, Fuel, Vol. 88, pp. 2373-2384, (2009).

8. Kantorek M. i inni: Możliwości technologiczne energetycznego wykorzystania mączki mięsnokostnej, Archiwum Spalania 2009. Vol. 9. pp. 135-149, (2009).

9. Kantorek M.. i inni: Możliwości wykorzystania mączki mięsno-kostnej jako paliwa w instalacjach energetycznych, Energetyka, Vol. 1, pp. 39-47, (2009).

10. Karcz H.. Kozakiewicz A., Sposób termicznej utylizacji odpadów zwierzęcych, Energetyka, Vol. 11, pp. 823-831, (2007).

11. Fryda L., Panopoulos K., Vourliotis P., Pavlidou E., Kakaras E., Experimental investigation of fluidised bed co-combustion of meat and bone meal with coals and olive bagasse, Fuel, Vol. 85, pp. 1685-1699, (2006).

12. Vermeulen I., Van Caneghem J., Block C., Dewulf W., Vandecasteele C., Environmental impact of incineration of calorific industrial waste: Rotary kiln vs. cement kiln, Waste Management, Vol. 32, pp. 1853-1863, (2012).

13. Orszulik E.. Lenkiewicz D., Współspalanie węgla kamiennego z mączką mięsno-kostną w kotłach rusztowych. Energetyka, Vol. 11, pp. 831-836, (2007).

14. McDonnell K., Desmond J., Leahy J.J., HowardHoldige R., Ward S., Behaviour of meat and bonemeal/peat pellets in a bench scale fluidized bed combustor, Energy, Vol. 26, pp.81-90, (2001).

15. Bis Z., Kotty fluidalne: teoria $i$ praktyka, Wydaw. Politechniki Częstochowskiej, Częstochowa, (2010).

16. Simeon O., Fluidized Bed Combustion, Taylor\&Francis, (2003).

17. Staroń P., Kowalski Z., Staroń A., Seidlerova J., Banach M., Residues from the thermal conversion of waste from the meat industry as a source of valuable macro- and micronutrients, Waste Management, Vol. 49, pp. 337-345, (2016).

18. Kantorek M., Energetyczny recykling mączki zwierzęcej, PhD Thesis [in Polish], Politechnika Wrocławska, (2015). 